\title{
Feasibility of lower-limb muscle power training to enhance locomotor function poststroke
}

\author{
Patrick Morgan, MS; ${ }^{1}$ Aaron Embry, DPT, MSCR; ${ }^{1-2}$ Lindsay Perry, DPT, NCS; ${ }^{1-2}$ Katy Holthaus, BS; ${ }^{1}$ Chris M. \\ Gregory, PhD, PT $^{1-3^{*}}$ \\ ${ }^{1}$ Department of Health Sciences and Research and ${ }^{2}$ Division of Physical Therapy, Medical University of South Carolina, \\ Charleston, SC; ${ }^{3}$ Ralph H. Johnson Department of Veterans Affairs Medical Center, Charleston, SC
}

\begin{abstract}
Poststroke motor control is characterized by greatly reduced muscle power generation. To date, the extent to which muscle power limits walking performance or whether its remediation should be a primary component of locomotor rehabilitation has yet to be established. The purpose of this study was to examine the feasibility and the effects of Poststroke Optimization of Walking using Explosive Resistance training, an intervention aimed at improving poststroke muscular and locomotor function. Twelve subjects (6-60 mo poststroke) participated in 24 training sessions ( 3 sessions/wk for $8 \mathrm{wk}$ ). Exercises included leg press, calf raises, and jump training, all performed at high concentric velocity, as well as trials of fast walking. We measured selfselected and fastest comfortable walking speeds as well as knee extensor and plantar flexor strength and power at pretraining, posttraining, and $8 \mathrm{wk}$ follow-up time points. In addition, we also performed a number of clinical assessments commonly used in poststroke rehabilitation trials. Following training, significant improvements in lower-limb muscle strength and power were realized and accompanied by improvements in self-selected as well as fastest comfortable walking speeds. No changes in clinical assessments resulted from training.
\end{abstract}

Key words: exercise, locomotion, locomotor function, muscle, optimization of walking, poststroke, rehabilitation, strengthening, stroke, walking.

\section{INTRODUCTION}

There are nearly 6 million people with stroke living in the United States and approximately 700,000 new strokes occurring annually. Stroke is the leading cause of longterm disability in this country, where 73 percent of those experiencing stroke have some degree of long-term disability [1-2]. Less than half of people with stroke progress to independent community ambulation [3]. Even among those who do regain the ability to walk, significant residual deficits persist and the majority of these individuals report limitations in mobility related to walking [3]. Following stroke, the most consistent gait impairment observed is slow walking speed. Importantly, improving walking speed is (1) independently related to overall health status, (2) a strong predictor of functional recovery, (3) reflective of both physiological and functional changes, and (4) the most often stated goal during rehabilitation [4]. As such, interventions aimed at improving functional walking status are critical for improving quality of life for hemiparetic individuals and their caregivers.

Abbreviations: $6 \mathrm{MWT}=6$-minute walk test, DGI $=$ Dynamic Gait Index, FCWS = fastest comfortable walking speed, FMA = Fugl-Meyer Assessment, $\mathrm{KE}=$ knee extensor, MVIC = maximum voluntary isometric contraction, $\mathrm{PF}=$ plantar flexor, POWER = Poststroke Optimization of Walking using Explosive Resistance, SSWS = self-selected walking speed, VA = Department of Veterans Affairs.

*Address all correspondence to Chris M. Gregory, PhD, PT; Department of Health Sciences and Research, Medical University of South Carolina, 77 President St, MSC 700, Charleston, SC 29425; 843-792-1078. Email: gregoryc@musc.edu http://dx.doi.org/10.1682/JRRD.2014.04.0109 
Hemiparesis, strictly defined as a muscular weakness or partial paralysis of half of the body, is seen in threequarters of individuals poststroke. It has been proposed that slow walking speeds following stroke are causally related to an inability to generate sufficient lower-limb power to meet the task demands of body forward progression. Decreased muscle power generation means that the necessary mechanical energy for the trunk and legs may not be available, thereby negatively affecting walking performance and decreasing functional independence. Muscle power generation involves both strength and velocity components and is determined by the force-generating capacity of the muscle as well as its speed of shortening. Although the loss of muscle mass, as well as the inability to activate paretic muscle, clearly contribute to the loss of muscle strength, these variables alone cannot account for the proportionally greater loss of muscle power than strength following stroke [5]. Pronounced velocity-dependent muscular deficits, in combination with substantial muscle weakness, significantly affect power generation when compared with neurologically healthy older counterparts [5-6]. Interestingly, muscle power is a significant predictor of functional ability to a greater extent than muscle strength in elderly subjects. In fact, direct comparisons of power and strength demonstrate that muscle power deficits consistently describe more of the variance in functional ability [7] and are associated with increased levels of dependence, greater risk of falls, and decreased walking speeds [8-10].

Although deficits in muscle power generation are linked to disability, data describing the effects of improving muscle power generation on functional performance following stroke are absent. By training individuals poststroke using a program that specifically targets impaired power generation, we expect neuromuscular adaptations to occur that translate to increased walking speeds. Thus, the purpose of this study was to examine the effects of $8 \mathrm{wk}$ of Poststroke Optimization of Walking using Explosive Resistance (POWER) training, a high-intensity and highvelocity lower-limb power training program, on poststroke muscular and locomotor function.

\section{METHODS}

\section{Subjects}

Twelve subjects between 6 and 60 mo poststroke participated in this study. Inclusion criteria were age 19 to 70 , ability to walk for a minimum of $10 \mathrm{~m}$ without sup- port from another person, lower than normal self-selected walking speed (SSWS) (i.e., $<1.2 \mathrm{~m} / \mathrm{s}$ ), no signs of orthopedic or visual problems that influence gait and balance, and no concomitant neurological disorders.

\section{Intervention}

Subjects completed the POWER training intervention, which included 24 training sessions (3 sessions/wk for $8 \mathrm{wk}$ ). It was determined a priori that all sessions had to be completed within a $10 \mathrm{wk}$ period for subjects to be considered compliant to the protocol. Exercises included leg press, calf raises, and jump training, all performed on a supine exercise device (Shuttle MVP Pro, Shuttle Systems Inc; Glacier, Washington). The number of sets performed ranged from two to three and the number of repetitions ranged from 8 to 15 , depending on the goals for progression for the given session. Exercise intensity (i.e., resistance and number of repetitions) was progressed throughout the duration of the intervention as tolerated by each individual. Unilateral training was performed, the goal being to maximize the gains possible in each leg. To emphasize muscle power generation during training, subjects were asked to perform the concentric phase of each exercise as quickly as possible. In addition, subjects also completed repeated $10 \mathrm{~m}$ trials of fast walking training (10 trials/session) at a minimum of 125 percent of SSWS to emphasize within-task power generation.

\section{Outcome Measures}

\section{Muscle Strength and Power}

Prior to training and at $2 \mathrm{wk}$ intervals throughout the intervention, muscle strength and power assessments were performed using an isokinetic dynamometer (Biodex Medical Systems Inc; Shirley, New York). Prior to testing, each subject was allowed a period of familiarization and warm-up. During strength testing, maximum voluntary isometric contraction (MVIC), defined as the highest torque achieved during three maximal contractions ( $\sim 3 \mathrm{~s}$ contractions separated by $60 \mathrm{~s}$ of rest), was determined bilaterally in the plantar flexor (PF) and knee extensor (KE) muscle groups.

During muscle power testing, peak isotonic power was assessed in the paretic and nonparetic KE muscle groups using an external resistance set at 40 percent of MVIC, because differences in lower-limb maximal velocity are shown to occur at relatively low external forces (e.g., 40\% 1 repetition maximum) and are most closely 
associated with gait velocity in older individuals [7]. To optimize reliability of the testing, each test was repeated five times.

During all dynamometric testing, subjects were instructed to (1) develop torque as fast as possible and (2) produce a maximal contraction. All contractions were performed with subjects positioned in the dynamometer and the axis of the dynamometer aligned with the joint axis of rotation. Proximal stabilization was achieved with straps at the chest, hips, and knee as appropriate.

\section{Overground Walking}

Prior to the first training session of each week, subjects walked on a $20 \mathrm{ft}$-long gait mat (GaitRite, CIR Systems Inc; Sparta, New Jersey) to measure SSWS and fastest comfortable walking speed (FCWS). Pretraining, posttraining, and follow-up data collections included SSWS and FCWS as well as spatiotemporal parameters of walking. Three trials at each speed were performed, with data averaged over the trials for analyses.

\section{Clinical Assessments}

A number of clinical assessments commonly used in the poststroke population were performed to determine the effects of our intervention beyond the behavioral measures of walking. Assessments included the lower-limb portion of the Fugl-Meyer Assessment (FMA) as well as the FMA synergy subsection, Stroke Impact Scale [1113], Berg Balance Scale, Dynamic Gait Index (DGI) [14], and 6-minute walk test (6MWT) [15]. All clinical assessments were performed by a licensed physical therapist.

\section{Data Analyses}

Statistical analyses were conducted using SPSS version 20 (IBM Corporation; Armonk, New York). Following confirmation of normality, group means were compared across time points (pretraining, posttraining, and follow-up) using a one-way analysis of variance. For all tests performed, the level of significance was set at $\alpha=0.05$. Post hoc correction for multiple comparisons was made using the Bonferroni method.

\section{RESULTS}

No adverse effects of training were reported. All but one subject completed the desired number of training sessions (i.e., 24) within the $10 \mathrm{wk}$ period of time allowed.
The one subject that did not complete training was withdrawn by the investigative team for noncompliance related to transportation issues. This subject did not report any adverse effects or perceptions of the training program. Data for this subject were not included in the analyses because they did not meet the a priori requirements for adherence.

\section{Muscle Strength and Power}

Following training, significant gains in bilateral PF and KE muscle strength were realized (Table 1). Specifically, PF MVIC increased by 25.0 and 23.3 percent in the paretic and nonparetic legs, respectively. Improvements in $\mathrm{KE}$ strength were not as large, with gains of 14.8 percent in the paretic side and 16.0 percent in the nonparetic side. Gains in KE peak power of 28.6 and 30.7 percent in the paretic and nonparetic limbs, respectively, were also found posttraining. Interestingly, gains in velocity of contraction were only found on the paretic side. With the exception of the KE peak velocity measures, all gains in muscle function were maintained throughout the followup period, with the indices of strength and power remaining significantly higher than pretraining values (Table 1).

\section{Overground Walking}

Both SSWS and FCWS increased following training (Table 1). SSWS increased from 0.71 to $0.92 \mathrm{~m} / \mathrm{s}$, and these gains were maintained $(0.91 \mathrm{~m} / \mathrm{s})$ at the follow-up time point. Similarly, FCWS increased from 1.10 to $1.51 \mathrm{~m} / \mathrm{s}$ posttraining, with speeds at follow-up $(1.30 \mathrm{~m} / \mathrm{s})$ still higher than pretraining values. The increase in SSWS resulted from increases in cadence (13.6\%) as well as both paretic $(13.0 \%)$ and nonparetic (10.1\%) step length, while changes in FCWS were primarily explained by faster cadences following training.

\section{Clinical Assessments}

No significant improvements in clinical assessments were found following training, although follow-up scores on the DGI were significantly higher than pretraining values (Table 2).

\section{DISCUSSION}

The results of this study demonstrate that $8 \mathrm{wk}$ (24 sessions) of POWER training is feasible to implement in individuals following stroke and that increases in lower-limb 
Table 1.

Muscle and locomotor function outcomes (mean \pm standard deviation).

\begin{tabular}{|c|c|c|c|}
\hline Outcome & Pretraining & Posttraining & Follow-Up \\
\hline \multicolumn{4}{|l|}{ Overground Walking } \\
\hline SSWS (m/s) & $0.71 \pm 0.39$ & $0.92 \pm 0.43^{*}$ & $0.91 \pm 0.43^{*}$ \\
\hline $\mathrm{FCWS}(\mathrm{m} / \mathrm{s})$ & $1.10 \pm 0.53$ & $1.51 \pm 0.78^{*}$ & $1.30 \pm 0.60^{*}$ \\
\hline \multicolumn{4}{|c|}{ Muscle Strength and Power } \\
\hline \multicolumn{4}{|c|}{ PF MVIC (ft/lb) } \\
\hline Paretic & $47.2 \pm 27.0$ & $59.3 \pm 28.2^{*}$ & $55.9 \pm 29.4^{*}$ \\
\hline \multicolumn{4}{|l|}{ KE MVIC (ft/lb) } \\
\hline Paretic & $93.8 \pm 30$ & $107.8 \pm 36.5^{*}$ & $111.4 \pm 31.2^{*}$ \\
\hline Nonparetic & $150.4 \pm 34.52$ & $174.4 \pm 41.5^{*}$ & $172.3 \pm 37.3^{*}$ \\
\hline \multicolumn{4}{|l|}{ KE Power (W) } \\
\hline Paretic & $6,369.0 \pm 3,524.1$ & $8,188.3 \pm 3,878.0^{*}$ & $8,064.6 \pm 2,421.1^{*}$ \\
\hline Nonparetic & $224.0 \pm 39.6$ & $230.2 \pm 58.8$ & $238.1 \pm 46.6$ \\
\hline
\end{tabular}

${ }^{*}$ Statistically significant difference compared with pretraining values $(p<0.05)$.

$\mathrm{FCWS}=$ fastest comfortable walking speed, $\mathrm{KE}=$ knee extensor, MVIC $=$ maximum voluntary isometric contraction, $\mathrm{PF}=$ plantar flexor, $\mathrm{SSWS}=$ self-selected walking speed.

Table 2.

Clinical assessments (mean \pm standard deviation).

\begin{tabular}{lccc}
\hline Clinical Assessment & Pretraining & Posttraining & Follow-Up \\
\hline FMA-S & $14.6 \pm 5.4$ & $15.5 \pm 5.1$ & $14.7 \pm 4.7$ \\
BBS & $44.7 \pm 11.6$ & $45.0 \pm 10.9$ & $46.8 \pm 12.4$ \\
DGI & $16.9 \pm 5.1$ & $16.5 \pm 6.3$ & $18.0 \pm 4.4^{*}$ \\
6MWT & $264.7 \pm 147.3$ & $319.1 \pm 160.6$ & $338.2 \pm 167.9$ \\
\hline
\end{tabular}

${ }^{*}$ Statistically significant difference compared with pretraining $(p<0.05)$.

$6 \mathrm{MWT}=6$-minute walk test, $\mathrm{BBS}=$ Berg Balance Scale, DGI $=$ Dynamic Gait Index, FMA-S $=$ Fugl-Meyer Assessment synergy subsection.

muscle strength and power as well as walking function may be realized. Unique aspects of POWER training include (1) the focus on high-velocity concentric contractions during resistive exercise (i.e., focus on muscle power generation) and (2) the combined use of taskspecific and resistive exercise.

Velocity-dependent muscular deficits following stroke appear to be unique to high-velocity concentric muscle actions, with normalized muscle power generation seemingly preserved during eccentric contractions, thus the focus on high shortening velocities in the present study [5]. Moreover, interventions targeting muscle power (i.e., training at concentric high velocities) in the older adults significantly increase muscle strength yet elicit an over twofold greater improvement in peak power compared with training at normal velocities [16-17]. The high-velocity component is suggested to be critical to elicit these responses, because losses in muscle power with aging (as well as stroke) appear to be due to greater declines in the velocity of contraction rather than the force generating component of muscle power production. In the present study, greater gains in muscle power compared with strength were noted, although with the present design we were not able to test the functional significance of strength versus power.

Progressive resistance training is widely accepted as the most effective method for increasing muscular strength. Traditional clinical perspectives, however, often caution against high-exertion activities (e.g., muscle strengthening) following stroke because it is thought that these approaches can worsen spasticity [18]. To date, 
contemporary investigations have failed to demonstrate exacerbation of spasticity with high-exertion exercises and these activities are increasingly recognized as critical components of rehabilitation treatment following stroke [19-21]. Though some studies have questioned the effect of muscle strengthening on functional performance poststroke [22], resistance training is shown to improve lower-limb strength and, when delivered at appropriate intensities, provide significant functional benefit [2324]. In fact, a recent quantitative review by Dickstein concluded that gains in lower-limb strength following resistance training have significant functional consequences in individuals poststroke [25].

Despite the relatively short duration of POWER training, the magnitude of increase in walking speed achieved in the present study $(0.21 \mathrm{~m} / \mathrm{s})$ is comparable with recent, more lengthy task-specific approaches [26-27]. Importantly, this change in SSWS is greater than the minimally clinically important difference recently reported in subacute poststroke subjects [28]. Furthermore, gains in walking speed following POWER training also exceed the values for clinically important change reported by Fulk et al. following outpatient physical therapy [29]. Fulk et al. suggest that changes that exceed 0.175 and $0.190 \mathrm{~m} / \mathrm{s}$ to be important to both patients and therapists, as well as useful for clinicians and researchers to set goals and interpret important change in patients poststroke [29].

Following stroke, there is a proportionally greater loss of muscle power than strength [5]. Pronounced velocitydependent muscular deficits, in combination with substantial muscle weakness, significantly affect power generation when compared with neurologically healthy aged counterparts [5-6]. In mobility-limited elders, direct comparisons of power and strength demonstrate that muscle power consistently describes more of the variance in functional ability [7] and deficits in power generation are associated with increased levels of dependence, greater risk of falls, and decreased walking speeds [8-10]. Our focus in this study was on the (in)ability of poststroke muscle to generate power both in and away from functional task performance and to determine the feasibility and effects of an intervention targeting lower-limb power generation in both the paretic and nonparetic legs on functional (locomotor) recovery. Following POWER training, robust improvements in walking performance were realized, suggesting the potential effect of this type of training following stroke.

The lack of improvement in the clinical assessments in this study is not altogether surprising. The relatively high-functioning sample of poststroke subjects studied, as evidenced by the pretraining scores on clinical assessments, likely contributed to the lack of change in these outcomes. Given that one of the questions in this study was whether muscle power training may increase walking function, we think it noteworthy that although differences in 6MWT were not statistically significant $(p=$ 0.06 ), the $72 \mathrm{~m}$ average improvement did exceed the minimal detectable change (i.e., $54.1 \mathrm{~m}$ ) reported for individuals following stroke [30] as well as the minimally clinically important difference $(30.1 \mathrm{~m})$ reported in individuals with heart failure [31].

\section{STUDY LIMITATIONS}

Limitations of this study require discussion. The design of this study does not allow determination of the effectiveness of this type of training because there is no comparison group. Although there seems little benefit in making comparisons to an untrained group (e.g., control group) in studies of chronic stroke, future studies should determine whether and to what extent changes in function differ between this type of training and other common approaches to enhance locomotor recovery. In addition, the two types of activities integrated into the training in this study (i.e., high-velocity resistance exercises and fast walking) limit conclusions as to the independent contributions of each to improvements in muscle function or walking performance. It is likely that both approaches would positively affect functional performance; and thus, there could be benefit in determining the independent effects of each type of training. Finally, the relatively small sample size may limit the generalizability of the findings. Although these limitations are important to consider when interpreting the results of this study, we think the magnitude of the effects found within the relatively short duration of training provide a foundation for future studies of this intervention approach.

\section{CONCLUSIONS}

Twenty-four sessions of POWER training appear feasible and well tolerated in individuals with chronic poststroke hemiparesis. Further, improvements in muscular and locomotor function in these individuals may result from this type of training. Future studies should determine 
the efficacy of this intervention compared with other established approaches to improve poststroke locomotor function.

\section{ACKNOWLEDGMENTS}

\author{
Author Contributions: \\ Study concept and design: C. M. Gregory, A. Embry. \\ Acquisition of data: C. M. Gregory, A. Embry, P. Morgan, L. Perry, \\ K. Holthaus. \\ Analysis and interpretation of data: C. M. Gregory, P. Morgan. \\ Drafting of manuscript: P. Morgan, C. M. Gregory, A. Embry, \\ L. Perry, K. Holthaus. \\ Critical revision of manuscript for important intellectual content: \\ P. Morgan, C. M. Gregory, A. Embry, L. Perry, K. Holthaus. \\ Statistical analysis: C. M. Gregory, P. Morgan. \\ Obtained funding: C. M. Gregory. \\ Study supervision: C. M. Gregory, A. Embry. \\ Financial Disclosures: We certify that no party having a direct inter- \\ est in the results of the research supporting this article has or will con- \\ fer a benefit on us or on any organization with which we are \\ associated, and if applicable, we certify that all financial and material \\ support for this research and work are clearly identified in the \\ "Acknowledgments" section of the article.
}

Funding/Support: This material was based on work supported by the Department of Veterans Affairs (VA), Office of Research and Development, Rehabilitation Research and Development Service (grant AHA-11BGIA7450016) and the Ralph H. Johnson VA Medical Center, Charleston, South Carolina.

Institutional Review: Informed consent was obtained from all subjects prior to participation, and all aspects of this study were performed in accordance with the protocol approved by the Institutional Review Board at the Medical University of South Carolina, Charleston, South Carolina.

Participant Follow-Up: The authors do not plan to inform participants of the publication of this study. However, participants have been encouraged to check the study Web site for updated publications.

\section{REFERENCES}

1. Lloyd-Jones D, Adams R, Carnethon M, De Simone G, Ferguson TB, Flegal K, Ford E, Furie K, Go A, Greenlund K, Haase N, Hailpern S, Ho M, Howard V, Kissela B, Kittner S, Lackland D, Lisabeth L, Marelli A, McDermott M, Meigs J, Mozaffarian D, Nichol G, O’Donnell C, Roger V, Rosamond W, Sacco R, Sorlie P, Stafford R, Steinberger J, Thom T, Wasserthiel-Smoller S, Wong N, Wylie-Rosett J, Hong Y; American Heart Association Statistics Committee and Stroke Statistics Subcommittee. Heart disease and stroke statistics - 2009 update: A report from the American Heart Association Statistics Committee and Stroke Statistics Subcommittee. Circulation. 2009;119(3):e21-181.

\section{[PMID:19075105]}

http://dx.doi.org/10.1161/CIRCULATIONAHA.108.191261

2. Post-Stroke Rehabilitation Guideline Panel. Post-stroke rehabilitation: Clinical practice guideline. Rockville (MD): U.S. Department of Health and Human Services, Public Health Service, Agency for Health Care Policy and Research; 1995.

3. Perry J, Garrett M, Gronley JK, Mulroy SJ. Classification of walking handicap in the stroke population. Stroke. 1995;26(6):982-89. [PMID:7762050]

http://dx.doi.org/10.1161/01.STR.26.6.982

4. Bohannon RW, Andrews AW, Smith MB. Rehabilitation goals of patients with hemiplegia. Int J Rehabil Res. 1988;11:181-84.

http://dx.doi.org/10.1097/00004356-198806000-00012

5. Clark DJ, Condliffe EG, Patten C. Reliability of concentric and eccentric torque during isokinetic knee extension in post-stroke hemiparesis. Clin Biomech (Bristol, Avon). 2006;21(4):395-404. [PMID:16403594] http://dx.doi.org/10.1016/j.clinbiomech.2005.11.004

6. Pohl PS, Duncan P, Perera S, Long J, Liu W, Zhou J, Kautz SA. Rate of isometric knee extension strength development and walking speed after stroke. J Rehabil Res Dev. 2002; 39(6):651-57. [PMID:17943667]

7. Bean JF, Kiely DK, Herman S, Leveille SG, Mizer K, Frontera WR, Fielding RA. The relationship between leg power and physical performance in mobility-limited older people. J Am Geriatr Soc. 2002;50(3):461-67. [PMID:11943041] http://dx.doi.org/10.1046/j.1532-5415.2002.50111.x

8. Bean JF, Leveille SG, Kiely DK, Bandinelli S, Guralnik JM, Ferrucci L. A comparison of leg power and leg strength within the InCHIANTI study: Which influences mobility more? J Gerontol A Biol Sci Med Sci. 2003;58(8): 728-33. [PMID:12902531] http://dx.doi.org/10.1093/gerona/58.8.M728

9. Chan BK, Marshall LM, Winters KM, Faulkner KA, Schwartz AV, Orwoll ES. Incident fall risk and physical activity and physical performance among older men: The Osteoporotic Fractures in Men Study. Am J Epidemiol. 2007;65(6):696-703. [PMID:17194749] http://dx.doi.org/10.1093/aje/kwk050

10. Kuo HK, Leveille SG, Yen CJ, Chai HM, Chang CH, Yeh YC, Yu YH, Bean JF. Exploring how peak leg power and usual gait speed are linked to late-life disability: Data from the National Health and Nutrition Examination Survey (NHANES), 1999-2002. Am J Phys Med Rehabil. 2006; 85(8):650-58. [PMID:16865019] http://dx.doi.org/10.1097/01.phm.0000228527.34158.ed

11. Duncan PW, Wallace D, Studenski S, Lai SM, Johnson D. Conceptualization of a new stroke-specific outcome measure: The Stroke Impact Scale. Top Stroke Rehabil. 2001; 
8(2):19-33. [PMID:14523743]

http://dx.doi.org/10.1310/BRHX-PKTA-0TUJ-UYWT

12. Duncan PW, Bode RK, Min Lai S, Perera S; Glycine Antagonist in Neuroprotection Americans Investigators. Rasch analysis of a new stroke-specific outcome scale: The Stroke Impact Scale. Arch Phys Med Rehabil. 2003;84(7): 950-63. [PMID:12881816] http://dx.doi.org/10.1016/S0003-9993(03)00035-2

13. Duncan PW, Lai SM, Bode RK, Perera S, DeRosa J. Stroke Impact Scale-16: A brief assessment of physical function. Neurology. 2003;60(2):291-96. [PMID:12552047] http://dx.doi.org/10.1212/01.WNL.0000041493.65665.D6

14. Shumway-Cook A, Woollacott MH. Motor control: Theory and practical applications. 2nd ed. Philadelphia (PA): Lippincott Williams \& Wilkins; 2001.

15. Solway S, Brooks D, Lacasse Y, Thomas S. A qualitative systematic overview of the measurement properties of functional walk tests used in the cardiorespiratory domain. Chest. 2001;119(1):256-70. [PMID:11157613] http://dx.doi.org/10.1378/chest.119.1.256

16. Fielding RA, LeBrasseur NK, Cuoco A, Bean J, Mizer K, Fiatarone Singh MA. High-velocity resistance training increases skeletal muscle peak power in older women. J Am Geriatr Soc. 2002;50(4):655-62. [PMID:11982665] http://dx.doi.org/10.1046/j.1532-5415.2002.50159.x

17. Bean JF, Herman S, Kiely DK, Frey IC, Leveille SG, Fielding RA, Frontera WR. Increased Velocity Exercise Specific to Task (InVEST) training: A pilot study exploring effects on leg power, balance, and mobility in community-dwelling older women. J Am Geriatr Soc. 2004;52(5):799-804.

[PMID:15086665] http://dx.doi.org/10.1111/j.1532-5415.2004.52222.x

18. Bobath B. Adult hemiplegia: Evaluation and treatment. 3rd ed. Oxford (England): Heinemann Medical Books; 1990.

19. Moreland JD, Goldsmith CH, Huijbregts MP, Anderson RE, Prentice DM, Brunton KB, O'Brien MA, Torresin WD. Progressive resistance strengthening exercises after stroke: A single-blind randomized controlled trial. Arch Phys Med Rehabil. 2003;84(10):1433-40.

[PMID:14586909] http://dx.doi.org/10.1016/S0003-9993(03)00360-5

20. Sharp SA, Brouwer BJ. Isokinetic strength training of the hemiparetic knee: Effects on function and spasticity. Arch Phys Med Rehabil. 1997;78(11):1231-36.

[PMID:9365354]

http://dx.doi.org/10.1016/S0003-9993(97)90337-3

21. Flansbjer UB, Miller M, Downham D, Lexell J. Progressive resistance training after stroke: Effects on muscle strength, muscle tone, gait performance and perceived participation. J Rehabil Med. 2008;40(1):42-48.

[PMID:18176736]

http://dx.doi.org/10.2340/16501977-0129
22. Sullivan KJ, Brown DA, Klassen T, Mulroy S, Ge T, Azen SP, Winstein CJ; Physical Therapy Clinical Research Network (PTClinResNet). Effects of task-specific locomotor and strength training in adults who were ambulatory after stroke: Results of the STEPS randomized clinical trial. Phys Ther. 2007;87(12):1580-1602. [PMID:17895349] http://dx.doi.org/10.2522/ptj.20060310

23. Teixeira-Salmela LF, Olney SJ, Nadeau S, Brouwer B. Muscle strengthening and physical conditioning to reduce impairment and disability in chronic stroke survivors. Arch Phys Med Rehabil. 1999;80(10):1211-18.

[PMID:10527076] http://dx.doi.org/10.1016/S0003-9993(99)90018-7

24. Lee MJ, Kilbreath SL, Singh MF, Zeman B, Davis GM. Effect of progressive resistance training on muscle performance after chronic stroke. Med Sci Sports Exerc. 2010; 42(1):23-34. [PMID:20010133] http://dx.doi.org/10.1249/MSS.0b013e3181b07a31

25. Dickstein R. Rehabilitation of gait speed after stroke: A critical review of intervention approaches. Neurorehabil Neural Repair. 2008;22(6):649-60. [PMID:18971380] http://dx.doi.org/10.1177/1545968308315997

26. Duncan PW, Sullivan KJ, Behrman AL, Azen SP, Wu SS, Nadeau SE, Dobkin BH, Rose DK, Tilson JK, Cen S, Hayden SK; LEAPS Investigative Team. Body-weightsupported treadmill rehabilitation after stroke. N Engl J Med. 2011;364(21):2026-36. [PMID:21612471] http://dx.doi.org/10.1056/NEJMoa1010790

27. Bowden MG, Behrman AL, Neptune RR, Gregory CM, Kautz SA. Locomotor rehabilitation of individuals with chronic stroke: Difference between responders and nonresponders. Arch Phys Med Rehabil. 2013;94(5):856-62. [PMID:23220082] http://dx.doi.org/10.1016/j.apmr.2012.11.032

28. Tilson JK, Sullivan KJ, Cen SY, Rose DK, Koradia CH, Azen SP, Duncan PW; Locomotor Experience Applied Post Stroke (LEAPS) Investigative Team. Meaningful gait speed improvement during the first 60 days poststroke: Minimal clinically important difference. Phys Ther. 2010; 90(2):196-208. [PMID:20022995] http://dx.doi.org/10.2522/ptj.20090079

29. Fulk GD, Ludwig M, Dunning K, Golden S, Boyne P, West T. Estimating clinically important change in gait speed in people with stroke undergoing outpatient rehabilitation. J Neurol Phys Ther. 2011;35(2):82-89. [PMID:21934363] http://dx.doi.org/10.1097/NPT.0b013e318218e2f2

30. Fulk GD, Echternach JL, Nof L, O'Sullivan S. Clinometric properties of the six-minute walk test in individuals undergoing rehabilitation poststroke. Physiother Theory Pract. 2008;24(3):195-204. [PMID:18569856] http://dx.doi.org/10.1080/09593980701588284 
31. Shoemaker MJ, Curtis AB, Vangsnes E, Dickinson MG. Clinically meaningful change estimates for the six-minute walk test and daily activity in individuals with chronic heart failure. Cardiopulm Phys Ther J. 2013;24(3):21-29. [PMID:23997688]

Submitted for publication April 21, 2014. Accepted in revised form November 3, 2014.
This article and any supplementary material should be cited as follows:

Morgan P, Embry A, Perry L, Holthaus K, Gregory CM. Feasibility of lower-limb muscle power training to enhance locomotor function poststroke. J Rehabil Res Dev. 2015; 52(1):77-84.

http://dx.doi.org/10.1682/JRRD.2014.04.0109

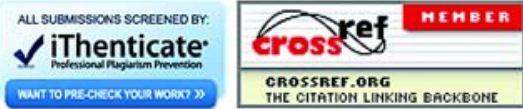

